\title{
Damage-less Chemical State Analysis by Using Soft X-ray Emission Spectroscopy in Low Voltage SEM
}

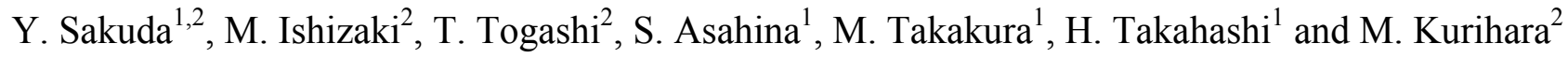 \\ 1. JEOL Ltd., Akisima, Tokyo, Japan \\ 2. Yamagata University, Yamagata, Japan
}

The development of low voltage (LV) FE-SEMs has been in progress and spatial resolution for observation less than $1.0 \mathrm{~nm}$ can now be achieved even at $1 \mathrm{kV}$. On the other hand, recent advanced nano materials are getting more complex and micronized. Therefore, chemical state analysis in FE-SEM is also important as well as the high spatial resolution imaging. Soft X-ray Emission Spectrometry (SXES) is one of the chemical state analysis methods. The advantage of SEM-SXES is applicability to bulk samples. However, it was known that the SXES is not suitable for electron beam sensitive samples because it needs high electron probe current to detect enough X-rays. In this report, we focused on the chemical state analysis with less electron damage using low voltage method and the cooling stage.

The SXES is possible to analyze chemical bonding states because it has high energy resolution at X-ray energy of about $200 \mathrm{eV}$ or even below such as $0.3 \mathrm{eV}$ at the Al Fermi edge [1]. The SXES is installed in the low voltage (LV) FE-SEM JSM-7800FPRIME. This LVFE-SEM can achieve a large probe current even under low voltage condition such as $20 \mathrm{nA}$ at $2 \mathrm{kV}$ with a $30 \mu \mathrm{m}$ diameter objective aperture, which is due to new design of high brightness Schottky emitter electron gun so called In lens Schottky plus. In addition, we can use a combined lens both electrostatic and magnetic to minimize C $c$. So-called Super Hybrid Lens (SHL) is equipped on JSM-7800FPRIME.

Prussian blue $\left(\mathrm{PB}, \mathrm{Fe}^{\mathrm{III}}{ }_{4}\left[\mathrm{Fe}^{\mathrm{II}}(\mathrm{CN})_{6}\right]_{3}\right)$ particles were observed by SEM-SXES. PB has multifunctionality and it has been used such as pigments since 300 years ago. Recently, many researches on PB nanoparticles were reported [2]. However, it is difficult to observe PB nanoparticles by SEM-SXES because it is easily subject to damage from electron beam. Figure 1 shows surface morphology of PB taken by SEM at different incident voltages. It was observed at $0.08 \mathrm{kV}$ in (a). The same region was observed at $0.08 \mathrm{kV}$ in (c) after the observation at higher voltage in (b) to confirm the damage caused by higher voltages. There is noticeable damage caused by higher energy electrons in (c). Figure 2 shows continuous observation at $0.08 \mathrm{kV}$. The same region was observed 3 times at $0.08 \mathrm{kV}$. There is less damage in these 3 images. Therefore, low voltage observation is good for SEM-SXES method considering the influence of beam damages.

Furthermore, the Peltier cooling stage of Deben is applied on the JSM-7800FPRIME. This stage can cool samples up to -50 degrees Celsius and reduce electron beam damage to samples. Figure 3 shows the comparison of spectra taken at $1.5 \mathrm{kV}$ with and without the cooling stage and $5 \mathrm{kV}$ by SXES. These spectra were obtained from the surface of PB. These results indicate that the sharpness of shoulder peak in the circle of Figure 3 is decreased as electron beam damage increase.

In summary, the combination of the low voltage method and the cooling stage is effective when electron beam sensitive samples are analyzed by using SEM-SXES. 


\section{References:}

[1] S. Asahina et al, APL Materials 2 (2014), p. 113317; doi: 10.1063/1.4902435

[2] A. Gotoh et al, Nanotechnology 18 (2007), doi:10.1088/0957-4484/18/34/345609

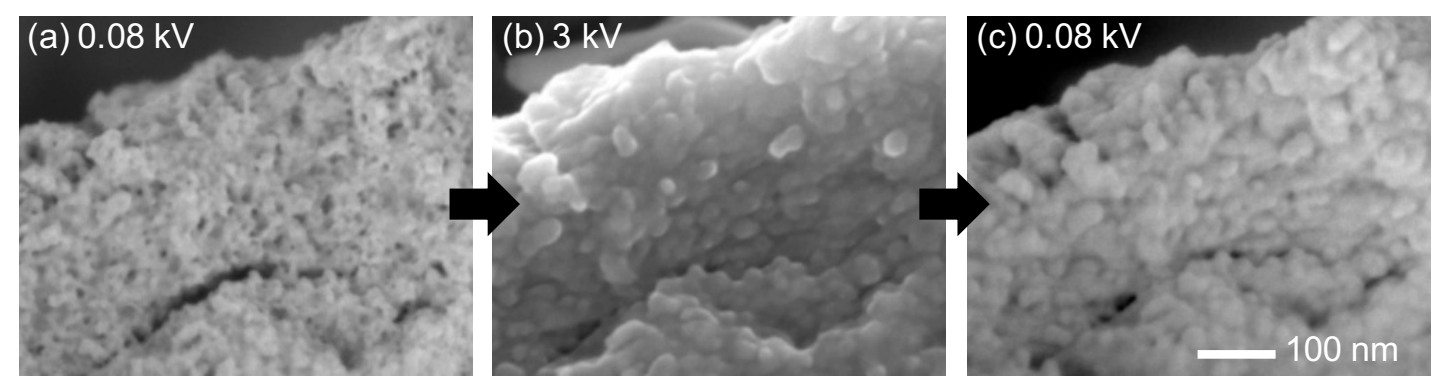

Figure 1. Surface morphology of PB taken by SEM at different incident voltages.

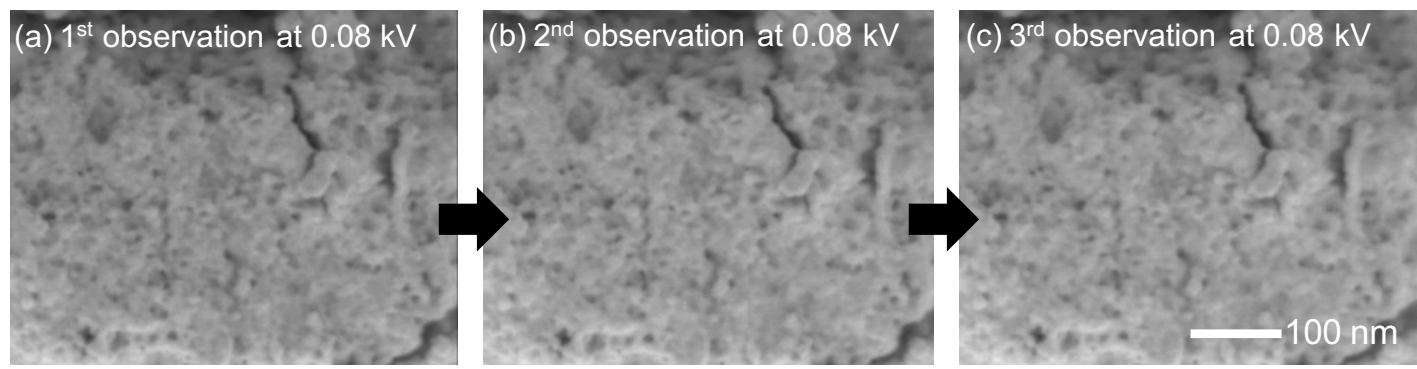

Figure 2. Continuous observation at $0.08 \mathrm{kV}$.

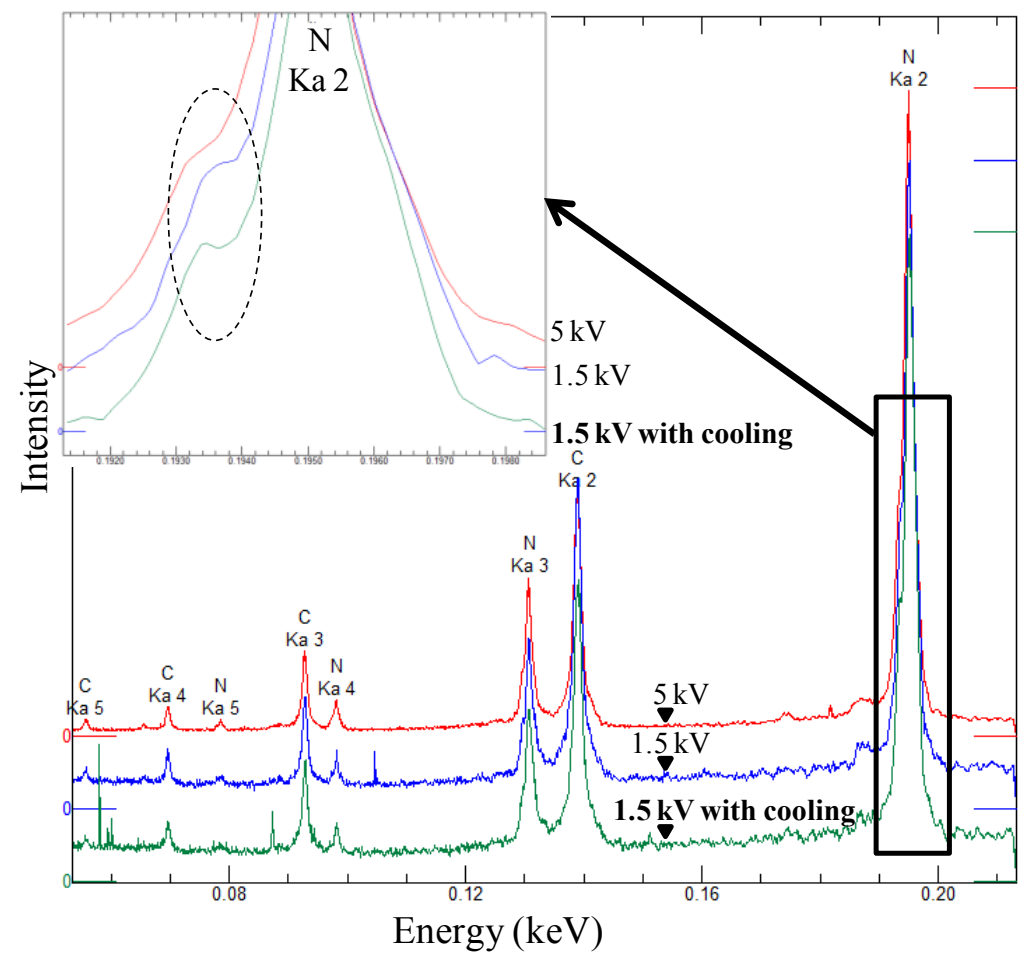

Figure 3. $\mathrm{N} \mathrm{K \alpha}$ spectra of $\mathrm{PB}$ at $1.5 \mathrm{kV}$ with and without cooling and $5 \mathrm{kV}$ taken by SXES. 